\title{
Measurement of left ventricular ejection fraction after acute myocardial infarction A serial cross sectional echocardiographic study
}

\author{
GERARD KAN, CEES A VISSER, KONG ING LIE, DIRK DURRER* \\ From the Department of Cardiology and Clinical Physiology, Wilhelmina Gasthuis, University of Amsterdam; and the \\ Interuniversity Cardiological Institute, Amsterdam, The Netherlands
}

SUMMARY Left ventricular ejection fraction was assessed by biplane cross sectional echocardiography in 65 patients with a first acute myocardial infarction on the first day. In 30 patients (group 1) measurements were repeated on the third day and in another 35 patients (group 2) at three months. Changes in ejection fraction of 0.05 or less were arbitrarily called insignificant. In group 1 only two patients showed a decrease of more than 0.1 between days 1 and 3, and both had an enzymatically confirmed infarct extension. The remaining patients had no complications. In group two 11 patients had decreases of more than 0.1 between day 1 and three months: three of them had an enzymatically confirmed reinfarction (perioperative in one) and four a possible reinfarction, and in two an angiographically confirmed left ventricular aneurysm developed. In two no complications occurred. The other complications that occurred were an enzymatically confirmed but small reinfarction, an angiographically confirmed but circumscript aneurysm, and an uncomplicated bypass operation in one patient each. These three patients had a small increase (between 0.05 and 0.1 ) in ejection fraction.

Reproducibility of the method of measuring the ejection fraction was assessed concurrently in 20 outpatients with a previous myocardial infarction who were studied twice on the same day (with a 30 minute interval) by two different observers. The mean absolute difference in ejection fraction between the paired observations was $0.036 \pm 0.023$ with a range of 0 to 0.07 . Thus only changes in ejection fraction of more than 0.1 correlate with clinically recognised complications. Changes between 0.05 and 0.1 may be due to spontaneous variability or to the limited reproducibility of the method.

Cross sectional echocardiography has been shown to be a potentially useful, non-invasive method of assessing left ventricular ejection fraction. Several reports have shown a good correlation with the ejection fraction measured by cineangiography ${ }^{1-13}$ or radionuclide angiography. 4914 To date reports of clinical applications have, however, been scarce. The purpose of the present study was to measure the ejection fraction sequentially in acute myocardial infarction and to correlate changes in ejection fraction in the acute and convalescent stage with the clinical course.

Requests for reprints to Dr G Kan, Academisch Medisch Centrum, University of Amsterdam, Meibergdreef 9, 1105 AZ Amsterdam, The Nertherlands.

*Professor Durrer died on 3 March 1984.

Accepted for publication 6 December 1983

\section{Patients and methods}

The patient population was derived from a study of 112 patients with acute myocardial infarction admitted to hospital between 1 July 1981 and 1 May 1982 in whom cross sectional echocardiography was attempted on admission. Of these, 90 had cross sectional echocardiograms of sufficient quality to allow volume calculations to be made from stop frames (success rate $80 \%$ ). The results of this study are to be published elsewhere. ${ }^{15}$ At the start of the study our aim was to determine whether the ejection fraction on admission could predict the subsequent development of severe pump failure, especially cardiogenic shock. During the last three months of the study we decided to examine newly admitted patients on the third day of 

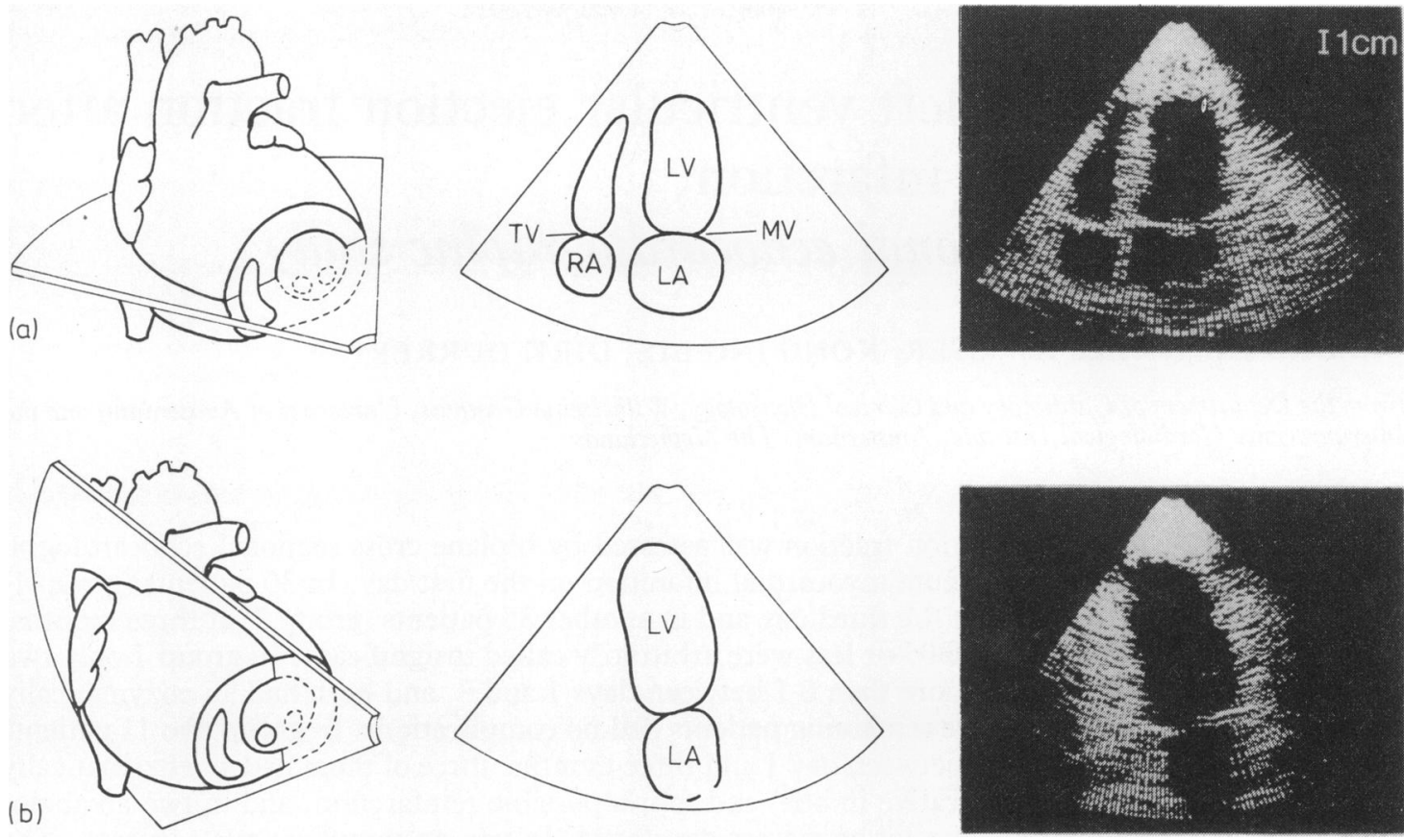

Fig. 1 Schematic representation (with cross sectional echocardiograms) of the two apical cross sections used for volume calculations: (a) four chamber view and (b) two chamber view. LA, left atrium; LV, left ventricle; $M V$, mitral valve; RA, right atrium; TV, tricuspid valve.

infarction (group 1) and at the same time those patients who were alive at three months after the acute event (group 2). All had a first transmural myocardial infarction as defined below. Group 1 consisted of 30 patients with a mean age $( \pm S D)$ of $59.5 \pm 14.1$ years and group 235 patients with a mean age of $58.0 \pm 14.8$ years.

The diagnosis of acute transmural myocardial infarction was based on a typical history, evolutionary electrocardiographic changes with the development of $Q$ waves, and an increase in creatine kinase $M B$ activity to levels exceeding twice the upper limit of normal, which in our institution is $4 \mathrm{U} / 1 .{ }^{16}$ For infarct localisation the criteria of Lipman et al were used. ${ }^{17}$ Septal, anterior, and lateral infarctions were grouped as anterior, and inferior and posterior infarctions as inferior.

\section{CROSS SECTIONAL ECHOCARDIOGRAPHY}

Patients were studied with a Smith-Kline Ekosector I machine with a $2.25 \mathrm{MHz}, 82^{\circ}$ rotary three element transducer. Two apical long axis views were recorded, namely the four and two chamber views ${ }^{18}$ (Fig. 1). To ensure an orthogonal relation between the two views we used a fluid filled calibrated ring with an air bubble fixed around the body of the transducer. The echocardiograms were recorded on a 0.5 inch Sanyo video cassette recorder for subsequent blind analysis. The electrocardiographic signal was recorded simultaneously to aid selection of end diastolic and end systolic still frames for volume measurements. Frames were rejected for volume analysis if the endocardium could not be clearly distinguished in both views (for example, due to drop out or overprojection of echoes from overlying lung tissue).

For each of the two views the endocardial outline was traced with a felt pen on a transparent sheet fixed to the surface of the monitor. The tape was first viewed in real time and slow motion and then frame by frame. The end diastolic frame was selected by visual inspection and with the aid of the electrocardiographic signal. By advancing the tape frame by frame the end systolic frame was selected from the same beat. If the tape had been advanced too far (for example, to frames showing increasing volume or beyond the moment of opening of the mitral valve) the end diastolic and end systolic frames were both traced anew from a single beat. Correctness of the traced outlines was checked by viewing the tape again at normal speed. For volume calculations we used the area-length method of Sandler and Dodge ${ }^{19}$ using the Vanguard M-35C projector and Decpack computer 
already in use for cineangiography. The results of the two and four chamber views were averaged. Neither the four nor the two chamber view includes the left ventricular outflow tract, which may contribute to the underestimation of left ventricular volume by cross sectional echocardiography. We have, however, previously shown that this approximation of the biplane area-length method, although theoretically not wholly correct, results in less underestimation of volume than a strictly biplane method or than Simpson's rule, whereas for the ejection fraction the results are comparable.

\section{DEFINITION OF COMPLICATIONS}

We considered only those complications that might have led to deterioration of the contractile state.

Infarct extension or reinfarction was diagnosed if a new period of ischaemic chest pain accompanied by electrocardiographic changes, such as development of new $Q$ waves or re-elevation of the ST segment, occurred in conjunction with a new rise in creatine kinase MB activity.

Possible infarct extension or reinfarction was diagnosed if ischaemic chest pain accompanied by electrocardiographic changes occurred without further increase in creatine kinase MB activity or without the enzyme being measured.

Left ventricular aneurysm was diagnosed if left ventricular cineangiography showed a bulge in the contour of the left ventricle that persisted in diastole and showed dyskinetic or akinetic behaviour. ${ }^{20}$ Cineangiography was carried out only for clinical reasons such as clinical suspicion of an aneurysm or postinfarction angina; the femoral approach was used.

\section{REPRODUCIBILITY}

The reproducibility of the technical aspects of left ventricular volume measurement was assessed concurrently in 20 stable outpatients with a previous myocardial infarction. This group consisted of 16 men and four women with a mean age of $59.8 \pm 14.2$ years, which was similar to that of the study patients. These patients were studied twice on the same day with a 30 minute interval by two different observers. Reproducibility, as assessed here, thus included the making of the two echocardiographic cross sections and the
Table 1 Comparative data of group 1 and group 2 at day 1

\begin{tabular}{|c|c|c|c|}
\hline & $\underset{(n=30)}{\text { Group } 1}$ & $\underset{(n=35)}{\text { Group } 2}$ & $\begin{array}{l}\text { Signifi- } \\
\text { cance }\end{array}$ \\
\hline $\begin{array}{l}\text { Age (years) } \\
\text { No of men } \\
\text { With anterior infarcts } \\
\text { Creatine kinase MB } \\
\text { activity (U/l) }\end{array}$ & $\begin{array}{l}59 \cdot 5 \pm 14 \cdot 1 \\
25 \\
23\end{array}$ & $\begin{array}{l}58 \cdot 0 \pm 14 \cdot 8 \\
25 \\
28\end{array}$ & $\begin{array}{l}\text { NS } \\
\text { NS } \\
\text { NS }\end{array}$ \\
\hline $\begin{array}{l}\quad \text { Mean } \\
\quad \text { Range } \\
\text { End diastolic volume }(\mathrm{ml}) \\
\text { End systolic volume }(\mathrm{ml}) \\
\text { Ejection fraction }\end{array}$ & $\begin{array}{l}160 \cdot 1 \pm 83 \cdot 2 \\
10-463 \\
123 \cdot 3 \pm 31 \cdot 4 \\
66 \cdot 2 \pm 21 \cdot 9 \\
0 \cdot 467 \pm 0.095\end{array}$ & $\begin{array}{l}137 \cdot 2 \pm 65 \cdot 9 \\
10-276 \\
127 \cdot 9 \pm 40 \cdot 0 \\
65 \cdot 3 \pm 28 \cdot 2 \\
0 \cdot 498 \pm 0 \cdot 108\end{array}$ & $\begin{array}{l}\text { NS } \\
\text { NS } \\
\text { NS } \\
\text { NS }\end{array}$ \\
\hline
\end{tabular}

NS, not significant ( $p>0.05)$.

volume calculations from the traced endocardial contours but did not include spontaneous variability with time.

\section{STATISTICS}

Within group comparisons were made by the paired $t$ test and between group comparisons by the unpaired $t$ test or $\chi^{2}$ analysis where appropriate. Reproducibility is expressed as the linear regression equation between the two assessments and as the mean $\pm S D$ of the absolute difference between the paired measurements.

\section{Results}

Groups 1 and 2 were comparable with respect to age, sex distribution, infarct localisation, mean maximum creatine kinase $\mathrm{MB}$ activity, left ventricular volume, and ejection fraction on day 1 (Table 1 ).

\section{GROUP 1}

\section{Group changes}

The values for end diastolic and end systolic volume and left ventricular ejection fraction (mean \pm SD) are given in Table 2. For the whole group there was a small but insignificant increase in both end diastolic and end systolic volume. The small increase in ejection fraction also failed to attain statistical significance.

\section{Individual changes}

Individual changes in ejection fraction are shown in Fig. 2. If a change of $\leqslant 0.05$ is considered arbitrarily

Table 2 Changes in left ventricular volume and ejection fraction between day 1 and day 3 in group 1 and between day 1 and three months in group 2 . Values are means $\pm 1 S D$

\begin{tabular}{|c|c|c|c|c|c|c|}
\hline & \multicolumn{3}{|l|}{ Group 1} & \multicolumn{3}{|l|}{ Group 2} \\
\hline & Day 1 & Day 3 & $p$ & Day 1 & 3 Months & $p$ \\
\hline $\begin{array}{l}\text { End diastolic volume (ml) } \\
\text { End systolic volume (ml) } \\
\text { Ejection fraction }\end{array}$ & $\begin{array}{l}123.3 \pm 31.4 \\
66 \cdot 2 \pm 21 \cdot 9 \\
0.467 \pm 0.095\end{array}$ & $\begin{array}{l}128 \cdot 8 \pm 31 \cdot 5 \\
67 \cdot 2 \pm 24 \cdot 5 \\
0.484 \pm 0.108\end{array}$ & $\begin{array}{l}\text { NS } \\
\text { NS } \\
\text { NS }\end{array}$ & $\begin{array}{l}127 \cdot 9 \pm 40.0 \\
65 \cdot 3 \pm 28 \cdot 2 \\
0.498 \pm 0.108\end{array}$ & $\begin{array}{l}136 \cdot 9 \pm 26.2 \\
75 \cdot 1 \pm 25 \cdot 7 \\
0.461 \pm 0.120\end{array}$ & $\begin{array}{l}\text { NS } \\
<0.05 \\
\text { NS }\end{array}$ \\
\hline
\end{tabular}



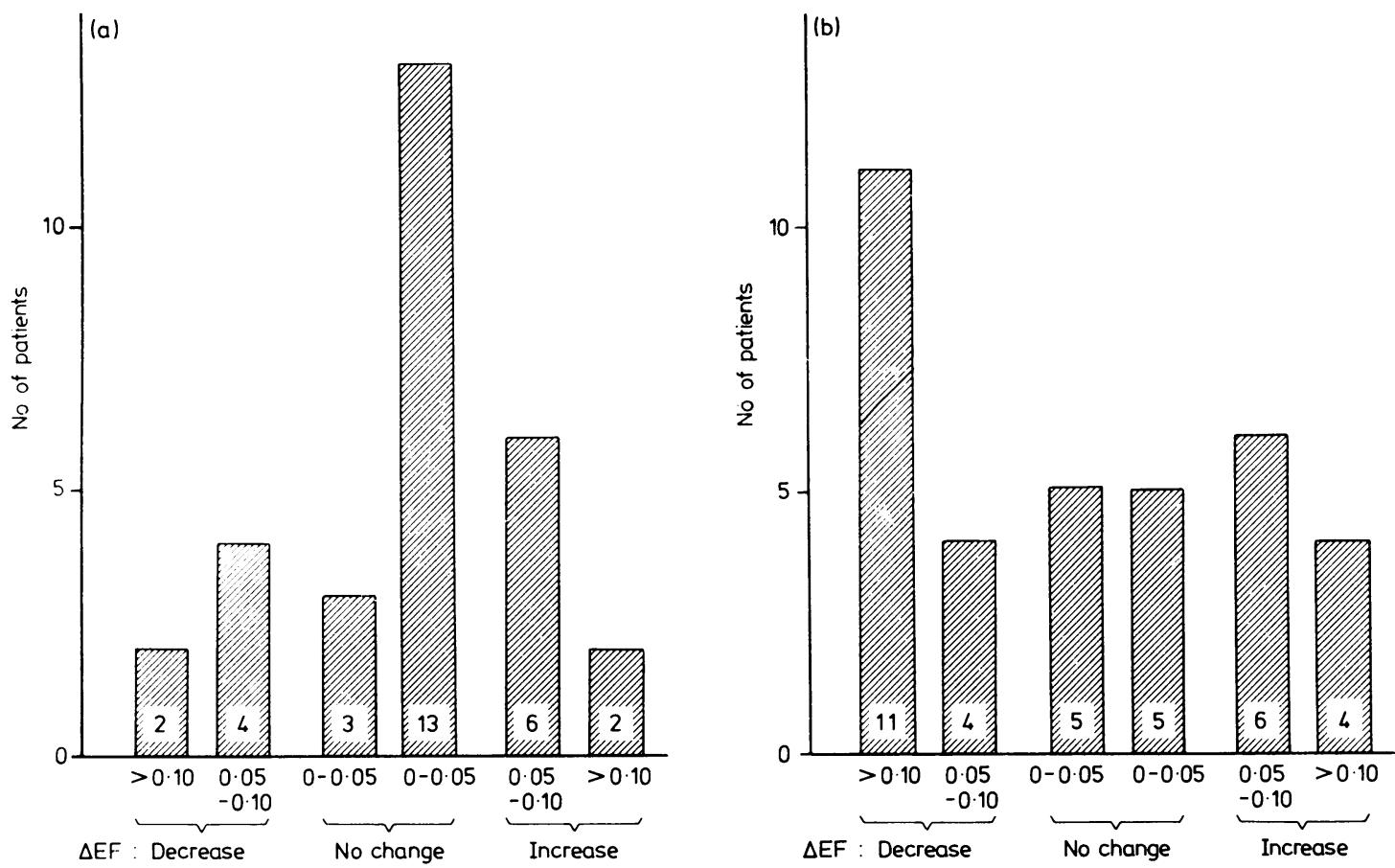

Fig. 2 Changes in left ventricular ejection fraction $(\triangle E F)$ by intervals of 0.05 (changes of $\leqslant 0.05$ were arbitrarily called "no change") (a) in the 30 patients in group 1 between days 1 and 3 (acute stage) and (b) in the 35 patients in group 2 between day 1 and three months (acute and chronic stages).

to represent no change 16 of the 30 patients had a stable ejection fraction. In none of these patients were complications observed. Similarly, no complications occurred in the four patients whose ejection fraction decreased by 0.05 to $0 \cdot 1$. Major decreases in ejection fraction, defined as decreases of more than $0 \cdot 1$, occurred in two patients with an enzymatically confirmed infarct extension: one had a decrease from 0.53 to 0.37 and the other from 0.41 to 0.29 . Two patients showed increases of more than 0.1 : one had pulmonary oedema on admission, which rapidly responded to treatment, with an ejection fraction increasing from 0.37 to 0.71 ; the other had no complications, and the ejection fraction increased from 0.48 to 0.59 .

\section{GROUP 2}

\section{Group changes}

Table 2 shows the values for volumes and ejection fraction on day 1 and at three months. For the whole group the increase in end diastolic volume was not

Table 3 Individual changes in ejection fraction in relation to complications in 11 patients (group 2) who had decreases of more than 0.1

\begin{tabular}{|c|c|c|c|c|c|c|}
\hline \multirow[t]{2}{*}{ Case No } & \multirow[t]{2}{*}{ Sex } & \multirow[t]{2}{*}{ Age (yr) } & \multirow{2}{*}{$\begin{array}{l}\text { Maximum } \\
\text { activity }(U / l)\end{array}$} & \multicolumn{2}{|c|}{ Ejection fraction } & \multirow[t]{2}{*}{ Complications } \\
\hline & & & & Day 1 & 3 Months & \\
\hline $\begin{array}{r}1 \\
2 \\
3 \\
4 \\
5 \\
6 \\
7 \\
8 \\
9 \\
10 \\
11\end{array}$ & $\begin{array}{l}F \\
M \\
M \\
M \\
F \\
M \\
M \\
M \\
M \\
M \\
M\end{array}$ & $\begin{array}{l}50 \\
41 \\
62 \\
71 \\
73 \\
49 \\
37 \\
51 \\
60 \\
82 \\
71\end{array}$ & $\begin{array}{l}28 \\
142 \\
136 \\
172 \\
183 \\
214 \\
202 \\
124 \\
74 \\
66 \\
140\end{array}$ & $\begin{array}{l}0.72 \\
0.52 \\
0.53 \\
0.48 \\
0.50 \\
0.36 \\
0.64 \\
0.54 \\
0.73 \\
0.52 \\
0.46\end{array}$ & $\begin{array}{l}0.52 \\
0.41 \\
0.37 \\
0.35 \\
0.29 \\
0.25 \\
0.37 \\
0.43 \\
0.45 \\
0.23 \\
0.35\end{array}$ & $\begin{array}{l}\text { Perioperative infarct } \\
\text { Infarct extension } \\
\text { Infarct extension } \\
\text { Possible reinfarction } \\
\text { Possible reinfarction } \\
\text { Possible reinfarction } \\
\text { Possible reinfarction } \\
\text { Aneurysm } \\
\text { Aneurysm } \\
\text { None } \\
\text { None }\end{array}$ \\
\hline
\end{tabular}

CK-MB, creatine kinase $\mathrm{MB}$ activity. 
significant, but the increase in end systolic volume was $(p<0.05)$. The decrease in ejection fraction was not significant.

\section{Individual changes}

The individual changes in group 2 are shown in Table 3. Decreases of more than 0.1 occurred in 11 patients; one of these had a documented perioperative infarction (she underwent bypass surgery for intractable angina after an inferior wall infarction), two had a documented reinfarction during convalescence, four had a possible reinfarction, and two developed an angiographically confirmed large ventricular aneưrysm. In two patients the decrease in ejection fraction could not be explained by any of these complications. Of these 11 patients, 10 had an anterior wall infarction, the only exception being the patient undergoing bypass surgery.

Four patients had decreases in ejection fraction between 0.05 and 0.1 ; their clinical course was uneventful. The same was true of the 10 patients whose ejection fraction showed no significant change. There were six patients whose ejection fraction increased between 0.05 and 0.1 : one patient had an enzymatically confirmed but small (maximum creatine kinase MB activity $12 \mathrm{U} / \mathrm{l}$ ) reinfarction, one developed an angiographically confirmed but circumscript left ventricular aneurysm, and one underwent uncomplicated bypass surgery for postinfarction angina.

Four patients had an increase in ejection fraction of more than 0.1 despite having no complications. On day 1 their ejection fractions were $0.48,0.46,0.42$, and 0.33 ; at three months these had increased to 0.70 , $0.60,0.55$, and 0.45 . The first of these patients had an inferior wall infarction, the latter three anterior wall infarctions.

\section{FORMAL REPRODUCIBILITY}

In the 20 outpatients in whom repeat echocardiograms and volume calculations were made the regression equation between the two assessments was: $y=9.3+0.77 x(r=0.82 ; p<0.01)$. The absolute difference between the two measurements averaged 0.036 $(\mathrm{SD} \pm 0.023$, range 0 to 0.07 ).

\section{Discussion}

Recently, several reports have appeared concerning changes in left ventricular ejection fraction in acute and chronic myocardial infarction measured by radionuclide methods. ${ }^{21-27}$ Apart from a preliminary report, ${ }^{14}$ serial measurement of ejection fraction by cross sectional echocardiography has not been described before. The present study shows that left ventricular volumes and ejection fraction are moderately stable in about half of the patients during the acute stage of uncomplicated infarction. This finding is in keeping with that of previous work at our institution, ${ }^{28}$ in which an index of regional wall motion rather than of global left ventricular function was used.

In the present study we found empirically that in most cases changes in ejection fraction greater than 0.1 could be related to complications such as infarct extension or reinfarction, possible reinfarction, or the development of a left ventricular aneurysm. Some patients, however, had similar changes that could not be related to complications and thus they had to be regarded as spontaneous variability (for example, as a result of changes in loading conditions or due to the recovery of ischaemic myocardium). Indeed, Wackers et al found that pronounced fluctuations in left ventricular ejection fraction (assessed by blood pool scintigraphy) during the first 24 hours of infarction occurred very frequently. ${ }^{29}$ Although the populations studied cannot be compared directly (our population consisted mainly of patients with an anterior wall infarction whereas that of Wackers et al ${ }^{29}$ had patients with mostly inferior wall infarctions), we probably encountered the same phenomenon, although less often. Since the left ventricular ejection fraction tends to be more stable in patients with low values, ${ }^{29}$ patients with anterior wall infarctions (which are generally larger than inferior infarctions) should be expected to show less spontaneous variability.

Changes between 0.05 and 0.1 were partly within the limits of technical reproducibility (which was up to 0.07 ) and partly the result of spontaneous variability. To be able to judge the clinical significance of changes in ejection fraction in individual patients a study comparable to that of Wackers et al ${ }^{29}$ would have to be performed. The relatively consistent results in our 20 stable patients with a previous infarction cannot be used for this purpose because they provided evidence only of technical reproducibility over a short time span. In our study the mean difference $( \pm S D)$ was $0.038 \pm 0.023$, which is greater than the $0.02 \pm 0.016$ in the frequently quoted study of Wackers et al. ${ }^{30}$ The largest difference observed (in patients with an abnormal ejection fraction) was 0.07 compared with 0.05 in the study by Wackers et al. ${ }^{30}$ Although cross sectional echocardiography in our study was thus less accurate than radioisotope imaging, technical improvements (for example, the use of video disks for forward and backward review, and light pen systems for tracing the endocardial contours directly from the screen) might improve the reproducibility of cross sectional echocardiographic volume analysis and make it comparable with that of radioisotope methods. These techniques would also make the procedure less tedious and time consuming. Although cross sectional echocardiography has its 
limitations-failure rate $20 \%$, underestimation of volume by about $20 \%$-no radiation is involved and it can be performed easily and repeatedly at the bedside even in critically ill patients.

\section{CONCLUSION}

We conclude that the measurement of left ventricular volume and ejection fraction by cross sectional echocardiography can be useful in assessing changes in left ventricular performance after acute myocardial infarction. Major decreases in ejection fraction could be related to complications such as an infarct extension or the development of an aneurysm. The method may provide more insight into the natural history of contractile abnormalities during the various stages of infarction and into the results of interventions in groups of patients. A study of the spontaneous variability in ejection fraction, especially during the acute phase of infarction, is still needed if the method is to be used to evaluate the results of interventions in individual patients.

\section{References}

1 Carr KW, Engler RL, Forsythe JR, Johnson AD, Gosink B. Measurement of left ventricular ejection fraction by mechanical cross-sectional echocardiography. Circulation 1979; 59: 1196-206.

2 Schiller NB, Acquatella H, Ports TA, et al. Left ventricular volume from paired biplane two-dimensional echocardiography. Circulation 1979; 60: 547-55.

3 Silverman NH, Ports TA, Snider AR, Schiller NB, Carlsson E, Heilbron DC. Determination of left ventricular volume in children: echocardiographic and angiocardiographic comparisons. Circulation 1980; 62: 548-57.

4 Folland ED, Parisi AF, Moynihan PF, Jones DR, Feldman CL, Tow DE. Assessment of left ventricular ejection fraction and volumes by real-time, two-dimensional echocardiography. A comparison of cineangiographic and radionuclide techniques. Circulation 1979; 60: 760-6.

5 Parisi AF, Moynihan PF, Feldman CL, Folland ED. Approaches to determination of left ventricular volumes and ejection fraction by real-time twodimensional echocardiography. Clin Cardiol 1979; 2: 257-63.

6 Kan G, Visser CA, Lie KI, Durrer D. Left ventricular volumes and ejection fraction by single-plane two-dimensional apex echocardiography. Eur Heart $\mathcal{f}$ 1981; 2: 339-43.

7 Jenni R, Vieli A, Hess O, Anliker M, Krayenbuehl HP. Estimation of left ventricular volume from apical orthogonal $2 \mathrm{D}$-echocardiograms. Eur Heart $\mathcal{f}$ 1981; 2: 217-25.

8 Edelman SK, Rowe DW, Pechacek LW, Garcia E. Left ventricular volumes and ejection fraction derived from apical 2D-echocardiography. Bulletin of the Texas Heart Institute 1981; 8: 344-53.

9 Starling MR, Crawford MH, Sorenson SG, Levi B, Richards KL, O'Rourke RA. Comparative accuracy of apical biplane cross-sectional echocardiography and gated equilibrium radionuclide angiography for estimating left ventricular size and performance. Circulation 1981; 63: 1075-84.

10 Kan G, Visser CA, Van Hulst J, Lie KI, Durrer D. Apical approach to
Simpson's rule for determination of left-ventricular volume and ejection fraction fournal of Cardiovascular Ultrasonography 1982; 1: 123-8.

11 Schnittger I, Fitzgerald PJ, Daughters GT, et al. Limitations of comparing left ventricular volumes by two-dimensional echocardiography, myocardial markers and cineangiography. Am f Cardiol 1982; 50: 512-9.

12 Erbel R, Schweizer P, Meyer J, Grenner H, Krebs W, Effert S. Left ventricular volume and ejection fraction determination by cross-sectional echocardiography in patients with coronary artery disease: a prospective study. Clin Cardiol 1980; 3: 377-83.

13 Kan G, Visser CA, Van Capelle FJL, Lie KI, Durrer D. Measurement of left ventricular ejection fraction by two-dimensional echocardiography: comparison of four different algorithms with single-plane and biplane cineangiography. Foumal of Cardiovascular Ultrasonography 1983; 2: 123-9.

14 Van Reet RE, Waggoner AD, Poliner LR, et al. Comparison of twodimensional echocardiography with radionuclide angiography in acute myocardial infarction [Abstract]. Circulation 1981; 64 (suppl IV): 46.

15 Kan G, Visser CA, Lie KI, Durrer D. Early two-dimensional echocardiographic measurement of left ventricular ejection fraction in acute myocardial infarction. Eur Hear $\mathcal{f}$ (in press).

16 Fiolet JWT, Willebrands AF, Lie KI, Ter Welle HF. Determination of creatine kinase isoenzyme MB (CK-MB): comparison of methods and clinical evaluation. Clin Chim Acta 1977; 80: 23-35.

17 Lipman BS, Massie E, Kleiger RE. Clinical scalar electrocardiography. 6th ed. Chicago: Year Book Medical Publishers, 1972: 219-22.

18 Henry WL, DeMaria A, Gramiak R, et al. Report of the American Society of Echocardiography committee on nomenclature and standards in two dimensional echocardiography. Circulation 1980; 62: 212-7.

19 Sandler H, Dodge HT. The use of single-plane angiocardiograms for the calculation of left ventricular volume in man. Am Heart $f$ 1968; 75: 325-34.

20 Gorlin R, Klein MD, Sullivan JM. Prospective correlative study of ventricular aneurysm. Mechanistic concept and clinical recognition. Am $\mathcal{J}$ Med 1967; 42: $512-31$.

21 Rigo P, Murray M, Strauss HW, et al. Left ventricular function in acute myocardial infarction evaluated by gated scintiphotography. Circulation 1974; 50: $678-84$

22 Schelbert HR, Henning H, Ashburn WL, Verba JW, Karliner JS, O'Rourke RA. Serial measurements of left ventricular ejection fraction by radionuclide angiography early and late after myocardial infarction. Am $\mathcal{f}$ Cardiol 1976; 38: 407-15.

23 Reduto LA, Berger HJ, Cohen LS, Gottschalk A, Zaret BL. Sequential radionuclide assessment of left and right ventricular performance after acute transmural myocardial infarction. Ann Intern Med 1978; 89: 441-7.

24 Wynne J, Sayres M, Maddox DE, et al. Regional left ventricular function in acute myocardial infarction: evaluation with quantitative radionuclide ventriculography. Am 7 Cardiol 1980; 45: 203-9.

25 Shah PK, Pichler M, Berman DS, Singh BN, Swan HJC. Left ventricular ejection fraction determined by radionuclide ventriculography in early stages of first transmural myocardial infarction. Am $\mathcal{f}$ Cardiol 1980; 45: 542-6.

26 Sanford CF, Corbett J, Nicod P, et al. Value of radionuclide ventriculography in the immediate characterization of patients with acute myocardial infarction. Am 7 Cardiol 1982; 49: 637-44.

27 Nemerovski M, Shah PK, Pichler M, et al. Radionuclide assessment of sequential changes in left and right ventricular function following first acute transmural myocardial infarction. Am Heart $\mathcal{f}$ 1982; 104: 709-17.

28 Visser CA, Lie KI, Kan G, Meltzer R, Durrer D. Detection and quantification of acute, isolated myocardial infarction by two-dimensional echocardiography. Am 7 Cardiol 1981; 47: 1020-5.

29 Wackers FJ, Berger HJ, Weinberg MA, Zaret BL. Spontaneous changes in left ventricular function over the first 24 hours of acute myocardial infarction: implications for evaluating early therapeutic interventions. Circulation 1982; 66: 748-54.

30 Wackers FJ, Berger HJ, Johnstone DE, et al. Multiple gated cardiac blood pool imaging for left ventricular ejection fraction: validation of the technique and assessment of variability. Am f Cardiol 1979; 63: 1159-66. 